Chronic Obstructive Pulmonary Diseases: Journal of the COPD Foundation

Original Research

\title{
Impact of a Medical Diagnosis on Decision to Stop Smoking and Successful Smoking Cessation
}

\author{
Hunter G. Lindsay ${ }^{1}$ Frederick S. Wamboldt, $\mathrm{MD}^{1,2}$ Kristen E. Holm, PhD, $\mathrm{MPH}^{1,3}$ Barry J. Make, $\mathrm{MD}^{1}$ \\ John Hokanson, MPH, $\mathrm{PhD}^{2}$ James D. Crapo, $\mathrm{MD}^{1}$ Elizabeth A. Regan, MD, $\mathrm{PhD}^{1,2}$ \\ and the COPDGene ${ }^{\circledR}$ Investigators
}

\section{Abstract}

Introduction: Smoking cessation counseling is a central part of the Medicare guidelines for lung cancer screening. With increasing age, many heavy smokers eventually stop smoking, however, factors influencing the decision to stop smoking are poorly understood. We postulated that declining health or physician-diagnosis of a medical condition may be associated with successful smoking cessation.

Methods: A total of 4448 current and former smokers in Phase 2 of the COPD Genetic Epidemiology (COPDGene ${ }^{\circledast}$ ) study answered a question about reasons for stopping smoking. Participants were classified as successful quitters ( $\mathrm{n}=3345)$, and unsuccessful quitters ( $\mathrm{n}=1003)$. Reasons cited for quitting were grouped as: medical diagnoses, social factors, symptoms. Logistic modeling of factors associated with successful quitting were adjusted for age, gender, race, and education.

Results: The most common factors cited for a quit attempt by all respondents were medical diagnoses (48\%), followed by social factors (47\%), and respiratory symptoms (36\%). Successful quitters were more likely to be older, male, and non-Hispanic White. An adjusted model found increased age, White race, education beyond high school, and male sex favored successful quitting while the cited medical diagnoses, social factors, and "other" reasons were associated with unsuccessful quitting. Fagerstrom Nicotine Dependence scores were $\geq 5$ in $54 \%$ of the unsuccessful group compared to $45 \%$ for successful quitters $(p<0.0001)$ suggesting some increased nicotine dependence in the unsuccessful quitters.

Conclusions: Medical diagnosis was the most common factor cited for considering a quit attempt by both successful and unsuccessful quitters; however, successful quitting was influenced by demographic factors and potentially the severity of nicotine dependence.

\footnotetext{
Abbreviations: COPD Genetic Epidemiology study, COPDGene ${ }^{\circledR}$; chronic obstructive pulmonary disease, COPD; computed tomography, CT; modified Medical Research Council Dyspnea Scale, mMRC; St George's Respiratory Questionnaire, SGRQ; Medical Outcomes Study 36Item Short Form Health Survey, SF-36; Global initiative for chronic Obstructive Lung Disease, GOLD; preserved ratio-impaired spirometry, PRISm; forced expiratory volume in 1 second, FEV $\mathbf{1}$; forced vital capacity, FVC; gastroesophageal reflux disease, GERD; coronary artery disease, CAD; physical health component score, PCS; mental health component score, MCS; square root of the wall area for an airway with an internal perimeter of $10 \mathrm{~mm}$, Pi10

Funding Support: The project described was supported by Award Number U01 HL089897 and Award Number U01 HL089856 from the National Heart, Lung, and Blood Institute. The content is solely the responsibility of the authors and does not necessarily represent the official views of the National Heart, Lung, and Blood Institute or the National Institutes of Health. COPDGene is also supported by the COPD Foundation through contributions made to an industry advisory board that has included AstraZeneca, Bayer Pharmaceuticals, Boehringer-Ingelheim, Genentech, GlaxoSmithKline, Novartis, Pfizer, and Sunovion.

Date of Acceptance: May 10, 2021 | Published Online Date: May 18, 2021

Citation: Lindsay HG, Wamboldt FS, Holm KE, et al; and the COPDGene Investigators. Impact of a medical diagnosis on decision to stop smoking and successful smoking cessation. Chronic Obstr Pulm Dis. 2021;8(3):360-370. doi: https://doi.org/10.15326/ jcopdf. 2020.0167
} 
1 National Jewish Health, Denver Colorado, United States

2 Department of Epidemiology, Colorado School of Public Health, Aurora, Colorado, United States

3 Department of Community and Behavioral Health, Colorado School of Public Health, Aurora, Colorado, United States

\section{Address correspondence to:}

Elizabeth A. Regan, MD, PhD

National Jewish Health

1400 Jackson St

Denver CO 80206

Phone: (303) 398-1531

Email: Regane@njhealth.org

\section{Keywords:}

smoking cessation, COPD, medical diagnoses, social factors, smoking symptoms

\section{Introduction}

Chronic cigarette smoking is associated with numerous adverse health effects including lung disease, cancer, cardiovascular disease, and premature death. ${ }^{1}$ Public health goals for current smokers emphasize smoking cessation to reduce these risks. ${ }^{2}$ The prevalence of smoking has decreased over the past 50 years, however, approximately $16 \%$ of the population are current smokers ${ }^{3}$ and up to $48 \%$ of the population over age 50 is a current or former smoker. ${ }^{4}$ Efforts to enhance smoking cessation can include education about the general risks of smoking, behavioral modifications, nicotine replacement, and medications., ${ }^{5,6}$ A structured program for smoking cessation that is part of the clinical practice guidelines from the U.S. Public Health Service, the 5-As (Ask, Advise, Assess, Assist, and Arrange) has been in place since $2000 .^{7,8}$ As part of the National Lung Screening Trial the effectiveness of the 5-A program was evaluated. Although the last 2 activities (assist and arrange) were found to be the activities associated most with successful quitting, they were less frequently employed by physicians. ${ }^{7,9}$ Interestingly, the identification of even a false positive lesion on lung cancer screening was also associated with increased smoking cessation. ${ }^{10}$ It is not clear how frequently physicians engage in specific advice around smoking cessation, ${ }^{11}$ but multiple sources report increased success in smoking cessation when physician engagement is present. ${ }^{12,13}$

With increasing age, many heavy smokers do eventually stop smoking, although some smokers persist despite lung disease and significant disability. ${ }^{14}$ Debate in the general community about the impact of smoking on health persists, in spite of strong scientific evidence, in large part fostered by commercial interests of the tobacco industry. Smokers may also demonstrate denial of health risks until confronted by critical diagnoses such as cancer, heart disease, or lung disease. ${ }^{15,16}$ By carefully evaluating a patient for known smoking-related illnesses, physicians may be able to provide specific diagnoses to their smoking patients and convey the known association to smoking. Smokers who have 30 pack years of smoking and who may now be eligible for lung cancer screening are of particular interest, due to the requirements under Medicare funding that these individuals receive advice about smoking cessation. If a smoker completes lung cancer screening without being given a cancer diagnosis, they may take a false reassurance that there has been no impact of smoking on their personal health, which would actually interfere with the goal to enhance smoking cessation. ${ }^{17}$ However, there has been less research on the impact of specific medical diagnoses on smokers' decisions to stop smoking.

We postulated that the decision to make a quit attempt might be associated with the development of lung disease, cardiovascular disease, cancer, or other medical conditions. We studied current and former smokers in the COPD Genetic Epidemiology $\left(\right.$ COPDGene ${ }^{\circledR}$ ) study who completed both a Phase 1 and Phase 2 study visit and reported on smoking status at both visits. We compared current and former smokers who reported the same status at both visits, as well as those who quit smoking or restarted smoking during the 5-year interval between Phase 1 and Phase 2 visits. Participants were asked about reasons for their decision to stop smoking.

\section{Methods}

\section{Cohort}

COPDGene is a cohort of 10,192 current and former smokers who were recruited for a study of genetic factors associated with chronic obstructive pulmonary disease (COPD) and subtypes of this complex and heterogeneous disease. The cohort was recruited between 2007 and 2011 at 21 clinical centers in the United States. The COPDGene study was approved by the institutional review board at 
each center, and all participants provided written, informed consent. Enrollment details, inclusion and exclusion criteria, and data collection from the Phase 1 visit has been described previously. ${ }^{18}$ Information collected during Phase 1 included: baseline spirometry, computed tomography (CT) findings of emphysema, gas trapping, and airway disease, respiratory symptoms including modified Medical Research Council (mMRC) dyspnea score, chronic bronchitis, and severe respiratory exacerbations, comorbid diseases, use of respiratory medications, 6-minute walk distance, and demographics. The St George's Respiratory Questionnaire (SGRQ) ${ }^{19}$ and the Medical Outcomes Study 36-Item Short Form Health Survey (SF-36) ${ }^{20}$ were used to assess respiratory and overall health-related quality of life.

Phase 2 return visits at a 5-year interval were completed between 2013 and 2017 and included questions about change in smoking status during the 5-year interval between Phases 1 and 2, as well as a question to describe factors that were associated with the decision to stop smoking. Of the 5611 participants who were seen for a Phase 2 visit, 4448 participants responded to the aforementioned questions regarding their decision to stop smoking and serve as the subset of the cohort used for the analysis within this paper.

\section{Smoking Status}

Participants were classified as current smokers based on a positive response to the question from the American Thoracic Society Respiratory questionnaire: "Do you smoke cigarettes now (as of 1 month ago)?" Participants were enrolled in the Phase 1 COPDGene study based on at least a 10 pack-year smoking history; however, most participants had a 30 to 50 pack-year smoking history. During the Phase 2 visit, participants were asked about their current smoking and a comparison was made of smoking status change between Phase 1 and Phase 2. This resulted in 4 groups based on smoking status: Current smokers (i.e., current smoking reported in Phase 1 and Phase 2), Former smokers (i.e., no current smoking reported in either Phase 1 or Phase 2), Current to Former smokers (i.e., Current smoker in Phase 1 and no current smoking in Phase 2), Former to Current smokers (No current smoking reported in Phase 1 and current smoking reported in Phase 2).

\section{Successful or Unsuccessful Quitters}

Participants were grouped as successful quitters if they had not resumed smoking in Phase 2 and had reported no current smoking in Phase 1. In addition, current smokers from Phase 1 who had quit by Phase 2 were also grouped as successful quitters. Unsuccessful quitters were current smokers in both Phase 1 and 2, and those Phase 1 former smokers who reported current smoking in Phase 2. For both successful and unsuccessful quitters, we analyzed those who responded to the question "If you ever stopped smoking, what factor affected your decision to stop?"

\section{Reasons to Stop Smoking}

Prior to the Phase 2 visit for the COPDGene study, a team of investigators developed a list of possible reasons that might have been considered by smokers in deciding to stop smoking. Potential reasons were derived from clinical experience in counselling smokers and reviewed by a questionnaire design committee for the study. Similar questions had been reported previously. ${ }^{21,22}$ The specific questions about the reasons to stop smoking and possible responses are detailed in Table 1. Each participant was permitted to mark all the reasons that applied to their decision to stop. The questions were grouped for analysis into Medical Diagnoses - 6 items, Symptoms -3 items, Social Factors -3 items, Other (unspecified) Reason, or No Reason. Participants who marked more than 8 reasons were excluded from the analysis (Table 2.)

\section{Fagerstrom Test for Nicotine Dependence}

Participants were queried about nicotine dependence using the questions from the Fagerstrom Test for Nicotine Dependence. ${ }^{23}$ Participants who scored greater than or equal to 5 (selected as midpoint of moderate nicotine dependence) were considered to have more potential nicotine addiction.

\section{Analysis}

Comparisons were made across the 4 groups of smokers using analysis of variance and student's $t$-test for continuous variables. For categorical variables, the groups were compared using Chi square and Fisher's Exact test. Logistic regression modeling was done with successful quitting versus unsuccessful quitting as the outcome. Covariates for the model 


\section{Table 1. Smoking Cessation Questions from Phase 2 of the COPDGene Study}

\begin{tabular}{l|c}
\hline If you ever stopped smoking, what factor affected your decision to stop? & "Yes" Responses \\
Medical Diagnoses & 862 \\
\hline 1. My doctor told me I have COPD & 254 \\
\hline 2. My doctor told me I had a heart attack, another heart problem or a stroke & 118 \\
\hline 3. My doctor told me I have cancer & 309 \\
\hline 4. My doctor told me that I have another medical condition & 1354 \\
\hline 5. My doctor told me smoking is bad for my health & 769 \\
\hline 6. I decided to stop because I have COPD & 2223 \\
\hline Any Medical Category Response & \\
\hline Symptoms & 696 \\
\hline 1. As I get older, I am less able to walk and exercise than people who don't smoke & 953 \\
\hline 2. I decided to stop because I didn't like coughing and bringing up phlegm & 641 \\
\hline 3. I didn't like the experience of smoking & 1660 \\
\hline Any Symptom Category Response & 1352 \\
\hline Social Factors & 675 \\
\hline 1. A family member or significant other person wanted me to stop & 1161 \\
\hline 2. Smoking is harder because of social disapproval and limits on smoking in public & 2146 \\
\hline 3. Smoking was too expensive & \\
\hline Any Social Category Response & 572 \\
\hline Other & 1926 \\
\hline 1. I decided to stop for no particular reason & \\
\hline 2. I decided to stop because of another (unnamed) reason & \\
\hline
\end{tabular}

\section{Table 2. Number of Responses by Participant}

\begin{tabular}{l|c|c|c}
$\begin{array}{l}\text { Number of } \\
\text { Answers } \\
\text { Marked }\end{array}$ & $\begin{array}{c}\text { Participants } \\
\text { with } \\
\text { Response }\end{array}$ & $\begin{array}{c}\text { Percentage } \\
\text { of Total with } \\
\text { Response } \\
\text { Number }\end{array}$ & $\begin{array}{c}\text { Cumulative } \\
\text { Percentage }\end{array}$ \\
\hline 1 & 1736 & $40.24 \%$ & $40.24 \%$ \\
\hline 2 & 920 & $21.33 \%$ & $61.57 \%$ \\
\hline 3 & 605 & $14.02 \%$ & $75.59 \%$ \\
\hline 4 & 398 & $9.23 \%$ & $84.82 \%$ \\
\hline 5 & 246 & $5.70 \%$ & $90.52 \%$ \\
\hline 6 & 187 & $4.33 \%$ & $94.85 \%$ \\
\hline 7 & 113 & $2.62 \%$ & $97.47 \%$ \\
\hline 8 & 54 & $1.25 \%$ & $98.72 \%$ \\
\hline 9 & 21 & $0.49 \%$ & $99.21 \%$ \\
\hline 10 & 14 & $0.32 \%$ & $99.53 \%$ \\
\hline 11 & 9 & $0.21 \%$ & $99.74 \%$ \\
\hline 12 & 2 & $0.05 \%$ & $99.79 \%$ \\
\hline 13 & 2 & $0.05 \%$ & $99.84 \%$ \\
\hline 14 & 7 & $0.16 \%$ & $100.00 \%$ \\
\hline
\end{tabular}

Participants who marked more than 8 reasons for stopping were excluded from analysis. They represented approximately $1 \%$ of the response. were selected to include basic demographics and education as a key variable likely to impact smoking decisions, along with the 5 categories of reasons to quit. Interaction terms for race and age and race and education were tested in the model and there was a significant interaction for race and education. Analyses were performed using JMP 13 and SAS (SAS Systems, Cary, North Carolina).

\section{Results}

There were 4448 participants who responded to the question about reasons for stopping smoking in Phase 2 of COPDGene. These participants were grouped into 4 categories: (1) Current smokers ( $\mathrm{n}=913)$; (2) Current to Former smokers ( $\mathrm{n}=668)$; (3) Former smokers ( $\mathrm{n}=2777)$; and (4) Former to Current smokers ( $\mathrm{n}=90)$. In addition to the 913 participants in the Current smoker group, there were 1130 currently smoking participants who did not respond to the question, presumably because they have never stopped smoking (Figure 1). Comparing current smokers who responded to those who did 


\section{Figure 1. Description of Cohort}

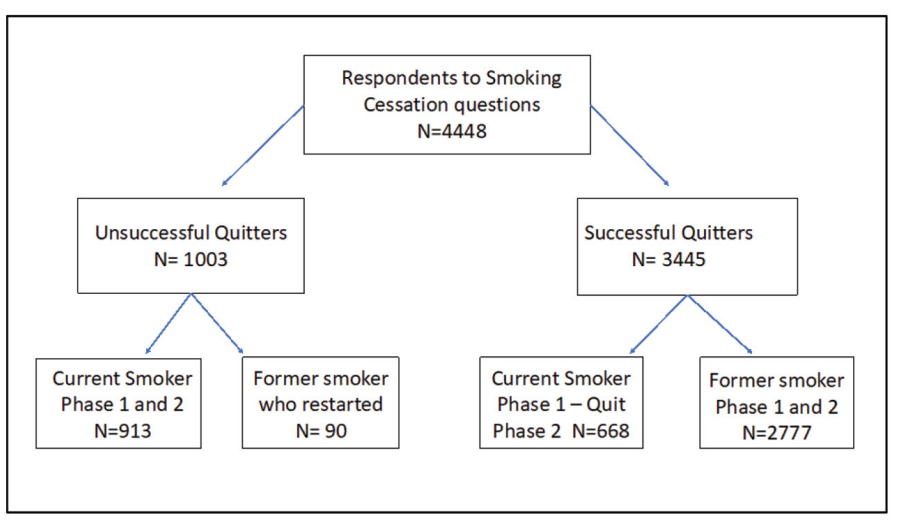

not, female participants were significantly more likely to respond than male participants ( $48 \%$ of female participants responded versus $41 \%$ of male participants), but otherwise the groups were similar in demographics of age and race. Characteristics of the 4 categories defined above are shown in Table 3 . There were no significant differences between them in pack years of smoking, or the occurrence of severe respiratory exacerbations. Current and Current to Former smokers included a greater proportion of African American participants. The distribution of the 4448 participants by Phase 1 Global initiative for chronic Obstructive Lung Disease (GOLD) stage was: 2034 (46\%) had normal spirometry, 402 (9\%) were GOLD 1; 873 (20\%) were GOLD 2; 496 (11\%) were GOLD 3; 131 (3.0\%) were GOLD 4 and 495 (11\%) were preserved ratio-impaired spirometry (PRISm) (17 participants were not assigned a GOLD stage because of a failed spirometry). ${ }^{24,25}$

Successful Quitters (Former smokers and Current to Former smokers) were significantly older and were more likely to be male. They had worse emphysema and gas trapping and had lower values for forced expiratory volume in 1 second $\left(F E V_{1}\right)$ percentage predicted, forced vital capacity (FVC) percentage predicted and FEV $1 / F V C$. The Former smokers had a smaller mean segmental airway wall area percentage, Pi10, and airway wall thickness compared to Current smokers. The Former smoker group also had significantly more comorbid hypertension, gastroesophageal reflux (GERD) and coronary artery disease (CAD) with a mean of 3.6 comorbidities (versus 3.0 for Current smokers), and $67.5 \%$ of Former smokers reporting more than 2 comorbidities (versus $54.4 \%$ of Current smokers). However, Former smokers had significantly better scores on the physical health component score (PCS) of the SF-36 and better overall scores on the SGRQ. All groups had significantly better mental health component scores (MCS) of the SF-36 when compared to Current smokers.

The list of 14 reasons for quitting were grouped into Medical Diagnoses, Symptoms, Social Factors, Other and No Reason for analysis as shown in Table 1. The number of responses for each reason to quit is shown in Table 1. Forty percent of the participants selected only 1 choice (Table 2). Of these participants, "Other reason" (unspecified) had the highest number of responses.

When considering all responses across all participants, $48 \%$ of respondents cited Medical Diagnoses as a reason to quit smoking (Table 4). Social Factors were the next most frequent in $47 \%$ of the participants, with "Other Reasons" in $42 \%$ and symptoms in 36\% (Table 4). The effect of Medical Diagnoses was greatest among Former to Current smokers, with 63\% reporting a medical diagnosis as a factor in considering quitting and was also strong in the Current to Former smoker group with $60 \%$. The Former smoker group had the least frequent citation of Medical Diagnoses as a factor for quitting (41\%) (Table 4).

There were 913 Current smoker participants who responded to the question of factors affecting the decision to stop smoking, indicating that they had unsuccessfully tried to stop in the past. There also were 90 former smokers in Phase 1 who reported returning to current smoking in Phase 2. These 2 groups together were considered to be Unsuccessful quitters $(\mathrm{n}=1003)$. Based on the smoking status at the time of the Phase 2 visit, we categorized participants as Successful quitters if they were either Former smokers in both Phase 1 and Phase 2, or they had stopped smoking between Phase 1 and 2 ( $n=3345)$. Characteristics of these 2 groups are shown in Table 5. The Unsuccessful quitters were generally younger, included a higher proportion of African Americans and were less likely to have COPD. The Unsuccessful quitters most strongly endorsed Medical Diagnoses as an important factor in deciding to quit or make a quit attempt.

The Fagerstrom Test for nicotine addiction was calculated for all current smokers in Phase 1 but had not been asked of former smokers. We compared the results of the Fagerstrom index among the participants 


\section{Table 3. Study Group Characteristics}

\begin{tabular}{|c|c|c|c|c|}
\hline & $\begin{array}{l}\text { Unsuccessful Qu } \\
\text { Current Smokers } \\
\text { in Phase } 1 \text { and } 2\end{array}$ & $\begin{array}{l}\text { uitters }(n=1003) \\
\text { Former Smoker } \\
\text { to Current }\end{array}$ & $\begin{array}{l}\text { Successful Quitter } \\
\text { Current Smoker Phase } \\
1 \text { to Former Smoker } \\
\text { Phase } 2\end{array}$ & $\begin{array}{l}\text { is }(\mathrm{n}=3445) \\
\text { Former Smokers } \\
\text { Phase } 1 \text { and } 2\end{array}$ \\
\hline Number & 913 & 90 & 668 & 2777 \\
\hline Age Phase 2 & $61.0(7.0)$ & $62.4(7.7)$ & $63.1(7.3)^{\mathrm{a}}$ & $69.6(8.0)^{\mathrm{a}}$ \\
\hline Gender (\% male) & $46 \%$ & $44 \%$ & $54 \%$ & $50 \%$ \\
\hline Race (\% African American) & $50 \%$ & $29 \%$ & $44 \%$ & $11 \%$ \\
\hline Pack Years & $40.6(21.9)$ & $37.8(19.4)$ & $43.2(23.4)$ & $43.3(24.9)$ \\
\hline FEV $_{1} \%$ Predicted Phase 2 & 80.1 (21.5) & $82.3(23.6)$ & $75.1(25.67)^{\mathrm{a}}$ & $77.0(26.3)^{a}$ \\
\hline FVC \% Predicted Phase 2 & $88.8(16.7)$ & $91.0(17.5)$ & $85.2(18.5)^{\mathrm{a}}$ & $86.1(18.4)^{a}$ \\
\hline FEV 1 /FVC Phase 2 & $0.69(0.13)$ & $0.69(0.14)$ & $0.67(0.16)^{a}$ & $0.66(0.16)^{a}$ \\
\hline SF-36 PCS & $42.7(10.8)$ & $43.7(11.8)$ & $42.0(11.4)$ & $44.2(11.3)^{\mathrm{a}}$ \\
\hline SF-36 MCS & $49.0(11.4)$ & $52.3(9.7)^{2}$ & $50.3(11.6)^{\mathrm{a}}$ & $53.9(9.5)^{\mathrm{a}}$ \\
\hline SGRQ Total Score & 27.1 (21.6) & $23.1(20.7)$ & $25.6(22.3)$ & $21.4(20.6)^{a}$ \\
\hline 6-Minute Walk Test & $\begin{array}{r}\mathrm{N}=900 \\
1296(420)\end{array}$ & $\begin{array}{r}\mathrm{N}=86 \\
1370(418)\end{array}$ & $\begin{array}{r}\mathrm{N}=643 \\
1237(448)^{\mathrm{a}}\end{array}$ & $\begin{array}{r}\mathrm{N}=2629 \\
1315(444)\end{array}$ \\
\hline mMRC Dyspnea Score & $1.3(1.5)$ & $1.2(1.4)$ & $1.4(1.5)$ & $1.2(1.4)^{\mathrm{a}}$ \\
\hline mMRC $(\% \geq 2)$ & $41 \%$ & $38 \%$ & $44 \%$ & $38 \%$ \\
\hline Chronic Bronchitis & $23 \%$ & $21 \%$ & $11 \%$ & $11 \%$ \\
\hline Severe Exacerbations & $11 \%$ & $11 \%$ & $13 \%$ & $9 \%$ \\
\hline Diabetes & $19 \%$ & $16 \%$ & $19 \%$ & $17 \%$ \\
\hline CAD & $11 \%$ & $13 \%$ & $13 \%$ & $18 \%$ \\
\hline Hypertension & $50 \%$ & $48 \%$ & $49 \%$ & $54 \%$ \\
\hline GERD & $24 \%$ & $27 \%$ & $27 \%$ & $36 \%$ \\
\hline Emphysema Percentage Phase 2 & $\begin{array}{r}\mathrm{N}=845 \\
3.1(5.8)\end{array}$ & $\begin{array}{r}\mathrm{N}=82 \\
4.1(7.5)\end{array}$ & $\begin{array}{r}\mathrm{N}=604 \\
6.1(9.9)^{\mathrm{a}}\end{array}$ & $\begin{array}{r}\mathrm{N}=2455 \\
7.2(10.4)^{\mathrm{a}}\end{array}$ \\
\hline Gas Trapping Percentage Phase 2 & $\begin{array}{r}\mathrm{N}=753 \\
16.2(16.0)\end{array}$ & $\begin{array}{r}\mathrm{N}=78 \\
17.1(19.0)\end{array}$ & $\begin{array}{r}\mathrm{N}=542 \\
22.0(19.8)^{\mathrm{a}}\end{array}$ & $\begin{array}{r}\mathrm{N}=2347 \\
23.3(19.8)^{\mathrm{a}}\end{array}$ \\
\hline Phase 2 Airway & $\mathrm{N}=845$ & $\mathrm{~N}=82$ & $\mathrm{~N}=606$ & $\mathrm{~N}=2456$ \\
\hline Wall Area \% & $51.8(8.9)$ & 51.7 (7.6) & $50.0(8.6)^{a}$ & $49.1(7.7)^{\mathrm{a}}$ \\
\hline Pi10 & $2.39(0.59)$ & $2.34(0.58)$ & $2.30(0.58)^{\mathrm{a}}$ & $2.20(0.54)^{\mathrm{a}}$ \\
\hline Airway Wall Thickness & $1.07(0.23)$ & $1.06(0.20)$ & $1.03(0.22)^{\mathrm{a}}$ & $1.01(0.21)^{\mathrm{a}}$ \\
\hline
\end{tabular}

$\mathrm{a}_{<0.05 \text { compared to current smokers }}$

$\mathrm{FEV}_{1}$ =forced expiratory volume in 1 second; FVC=forced vital capacity; SF-36 PCS=Medical Outcomes Study 36-Item Short Form-physical health component score; SF-36 MCS=Medical Outcomes Study 36-Item Short Form -mental health component score; SGRQ=St George's Respiratory Questionnaire; mMRC=modified Medical Research Council; CAD=coronary artery disease; GERD=gastroesophageal reflux disease; Pi10=square root of the wall area for an airway with an internal perimeter of $10 \mathrm{~mm}$ estimated from a regression of measured airways.

who stopped smoking after Phase 1 (Successful quitters, $n=621$ ) to those who continued to smoke in Phase 2, but reported quit attempts (Unsuccessful quitters, n=867). The Unsuccessful quitters had significantly higher Fagerstrom scores at Phase 1 (4.7 versus 4.1, $p=<0.0001$ ) than the Successful quitter group, and $54 \%$ of the Unsuccessful quitters had a score $\geq 5$ compared to $45 \%$ of the Successful quitters.

The strongest predictor of successful quitting in the logistic model was increasing age followed by male sex, non-Hispanic White race and higher education level. The impact of various categories of potential factors on the success of quitting was: reports of being influenced by Medical, No Particular Reason, and Social Factors were associated with less success in quitting. Other Unknown Reason and Social Factors were not significant. (Table 6) 


\section{Table 4. Reasons to Quit by Smoking Status Group}

\begin{tabular}{l|c|c|c|c|c|c}
\hline & Overall & $\begin{array}{c}\text { Current } \\
\text { Smokers }\end{array}$ & $\begin{array}{c}\text { Former to } \\
\text { Current Smokers }\end{array}$ & $\begin{array}{c}\text { Current to } \\
\text { Former Smokers }\end{array}$ & $\begin{array}{c}\text { Former } \\
\text { Smokers }\end{array}$ & $\begin{array}{c}\text { Significance } \\
\text { (ChiSq) }\end{array}$ \\
\hline Number & 4448 & 913 & 90 & 668 & 2777 & \\
\hline Medical Diagnoses & $48 \%$ & $60 \%$ & $63 \%$ & $60 \%$ & $41 \%$ & $<.0001$ \\
\hline Symptoms & $36 \%$ & $39 \%$ & $41 \%$ & $42 \%$ & $33 \%$ & $<.0001$ \\
\hline Social Factors & $47 \%$ & $49 \%$ & $64 \%$ & $50 \%$ & $45 \%$ & 0.0003 \\
\hline No Reason & $12 \%$ & $17 \%$ & $14 \%$ & $13 \%$ & $11 \%$ & 0.0003 \\
\hline Other Reason & $42 \%$ & $35 \%$ & $30 \%$ & $36 \%$ & $46 \%$ & $<.0001$ \\
\hline
\end{tabular}

\section{Table 5. Characteristics of Successful and Unsuccessful Quitters}

\begin{tabular}{|l|r|r|r}
\hline $\mathbf{N}$ & Unsuccessful Quitters & Successful Quitters & $p$ value \\
\hline Age & 1003 & 3445 & $<0.0001$ \\
\hline Gender (Male) & $55.5(7.1)$ & $62.8(8.3)$ & 0.006 \\
\hline Race (African American) & $46 \%$ & $50.6 \%$ & $<0.0001$ \\
\hline Education - High School or Greater & $48 \%$ & $17 \%$ & 0.0001 \\
\hline Pack Years Cigarette Smoking & $86 \%$ & $93 \%$ & 0.8702 \\
\hline Diagnosis of COPD Based on Spirometry & $43.5(22.5)$ & $43.6(24.8)$ & $<0.0001$ \\
\hline Reasons to Quit & $42 \%$ & $47 \%$ & \\
\hline$\quad$ Medical Diagnoses & $\mathrm{N}=972$ & $45 \%$ & $<0.0001$ \\
\hline \multicolumn{1}{|c|}{ Symptoms } & $60 \%$ & $35 \%$ & 0.0103 \\
\hline$\quad$ Social Factors & $40 \%$ & $46 \%$ & 0.0112 \\
\hline$\quad$ No Particular Reason & $50 \%$ & $11 \%$ & $<0.0001$ \\
\hline$\quad$ Other (unknown) Reason & $16 \%$ & $44 \%$ & $<0.0001$ \\
\hline Fagerstrom Score for Nicotine dependence $\geq \mathbf{5}$ & $35 \%$ & $45 \%$ & $<0.0001$ \\
\hline
\end{tabular}

\section{Table 6. Logistic Regression Model for Successful Quitting}

\begin{tabular}{l|c|c|r|r} 
& Direction of Effect & \multicolumn{2}{c}{ Odds Ratio } & 95\% Confidence Interval Significance \\
\hline Age & $\Uparrow$ & 1.10 (unit odds/year) & $1.09-1.11$ & $<0.0001$ \\
\hline Medical Diagnoses & $\Downarrow$ & 0.63 & $0.54-0.76$ & $<0.0001$ \\
\hline No Particular Reason & $\Downarrow$ & 0.59 & $0.47-0.75$ & $<0.0001$ \\
\hline Non-Hispanic White Race & $\Uparrow$ & 1.72 & $1.33-2.23$ & $<0.0001$ \\
\hline Race ${ }^{a}$ Education & Interaction & & & 0.0012 \\
\hline High School Education or Better & $\Uparrow$ & 1.38 & $1.07-1.77$ & 0.01 \\
\hline Male Gender & $\Uparrow$ & 1.20 & $1.02-1.40$ & 0.02 \\
\hline Social Factors & $\Downarrow$ & 0.77 & $0.65-0.91$ & 0.002 \\
\hline Other (unknown) Reason & Not Significant & 1.16 & $1.02-1.42$ & 0.08 \\
\hline Symptoms & Not Significant & 1.07 & $0.90-1.26$ & 0.46 \\
\hline
\end{tabular}

${ }^{\mathrm{a}}$ An interaction term between race and education that was significant in the model.

\section{Discussion}

The factors associated with smoking cessation in this analysis showed that medical events and medical risks are important in how smokers think about quitting, but do not provide a simple answer to the problem of improving successful quitting. In a cohort of heavy, current and former smokers, the most common reason cited to quit smoking was medical diagnosis. However, this reason was cited by the unsuccessful quitters even more frequently than by the successful quitters. A wealth of studies has shown that smokers 
want to quit but are strongly impacted by a variety of barriers including the addictive qualities of nicotine and smoking. A review by McCaul et al found a similar result over multiple studies of both current and former smokers - former smokers cite medical/ health reasons most commonly but current smokers have even greater focus on health as a reason to quit. $^{26}$ An additional factor may be recall bias since the mean (standard deviation) time since quitting in the successful quitter group was 17.5 (11.9) years.

Determining factors that will motivate chronic smokers to quit successfully is critical to improving public health and reducing the impact of smoking on risk of several major diseases. Smoking cessation is associated with slower rates of decline in lung function and decreased risk of cardiovascular disease. ${ }^{27,28}$ The current national guidelines on smoking cessation emphasize the importance of going beyond simple advice to quit and providing assistance with classes, counseling, and pharmacotherapy. ${ }^{8}$ Several studies have shown that actually assisting the patient with these strategies are associated with increased quitting success. ${ }^{7,9}$

We found significant differences between smokers who stop smoking and those who continue to smoke. Current smokers were often younger and were less likely to have encountered serious medical problems related to smoking. A physician diagnosis of a serious medical condition such as COPD, cancer, cardiovascular disease, or another problem was cited as an important factor to consider stopping smoking. Social factors including family wishes, social disapproval, and cost were also important. Surprisingly, symptoms such as cough and phlegm, or difficulty exercising were less influential in the decision to stop smoking, and this is corroborated by Current smokers who reported more chronic bronchitis and worse dyspnea symptoms compared to successful Former smokers.

The mean age difference between Former smokers and Current smokers in our cross-sectional study suggests that over time, many smokers will quit smoking. However, we also note that Former smokers tend to be stable in their smoking status. They appear to have made the decision to quit, often years ago and have been successful and largely stable. They report that medical diagnoses and social factors were both important in their decision to quit but have the highest proportion of "other" reasons. More recent quitters (those who quit during the 5-year interval of this study, i.e., the Current to Former Group) appear to be intermediate between the Current and Former smoker groups with increasing evidence of lung disease based on spirometry and CT scans, and increased chronic bronchitis and less comorbid disease. They report a strong impact of medical diagnosis on their decision to quit and the time since quitting is much shorter than in the Former group. They are distinguished from the Current smoker group in part by their slightly lower nicotine addiction rates based on Fagerstrom scores.

Whereas the Former smoker group appears settled, the other groups who report multiple attempts to quit appear to oscillate between current smoking and cessation. These individuals report multiple quit attempts and in the subset who remained current smokers, they had higher Fagerstrom scores suggesting a somewhat greater addiction to nicotine. Although they reported a strong impact of medical diagnoses on their efforts to quit, they were not successful in quitting.

The results of this study suggest ways to improve smoking cessation. Physicians play an important role in informing smokers about medical diagnoses when they become apparent. ${ }^{5}$ As lung cancer screening with chest CT scans becomes a standard practice, physicians should consider whether patients should be informed about other smoking-related diseases such as emphysema that are identified on those scans. Knowledge of these conditions may represent a turning point for a smoker that could motivate them to succeed in smoking cessation. ${ }^{17}$

Assessment of nicotine addiction severity, as an adjunct to lung cancer screening and enhanced diagnostic screening, may also identify patients who could benefit from medication or more intensive counseling. Variation in nicotine addiction appears to play a role in how successful a motivated patient may be in achieving stable smoking cessation. The number of participants in the current study was too small to assess genetic factors in this regard, but earlier work has shown significant heritability in nicotine dependence ${ }^{29}$ and a variant in the CHRNA4 nicotinic acetylcholine receptor gene has been associated with nicotine dependence. ${ }^{30}$

Strengths of this study include the large number of participants and broad inclusion of smokers with and without COPD. Participants were well characterized in 
terms of severity of symptoms, function, quality of life, and CT findings. The goal of this paper was to explore specific reasons associated with smoking cessation. We selected questions based on 3 potential factors (medical diagnoses, symptoms, and social factors), but discovered that "other reasons" were equally important. Permitting multiple responses allowed participants to fully delineate the variety of factors contributing to the complex decision to quit smoking but did not allow us to determine the most important factor for each participant. Further study (including focus groups) could be used to define the specifics of "other reasons" and could be used to determine a hierarchy in influential factors. Limitations included the problem of recall bias and the fact that "other reasons" and "no particular reason" were frequently cited. These findings suggest that we have not captured aspects of how smoking cessation decisions are made and completed. A further limitation is that the questions used were not derived from a validated instrument. Smoker status over time was ascertained from participant self-report and was not verified with cotinine levels or other confirmations.

Our study confirms the negative impact of chronic smoking on lung disease and identifies the potential importance of medical diagnoses to smokers considering smoking cessation. Integrating the diagnosis of other smoking-related medical diseases into lung cancer screening programs may improve smoking cessation rates and could also allow early treatment when available.

\section{Declaration of Interest}

$\mathrm{KEH}$ reports personal fees from AlphaNet, Inc., unrelated to the submitted work.

No other authors report potential conflicts of interest. 


\section{References}

1. National Center for Chronic Disease Prevention and Health Promotion (US) Office on Smoking and Health. The Health Consequences of Smoking-50 Years of Progress: A Report of the Surgeon General. Centers for Disease Control and Prevention; 2014.

2. Armour BS, Finkelstein EA, Fiebelkorn IC. State-level Medicaid expenditures attributable to smoking. Prev Chronic Dis. 2009;6(3):A84.

3. Jamal A, Phillips E, Gentzke AS, et al. Current cigarette smoking among adults - United States, 2016. MMWR Morb Mortal Wkly Rep. 2018;67(2):53-59. doi: https://doi.org/10.15585/mmwr.mm6702a1

4. Regan EA, Lynch DA, Curran-Everett D, et al. Clinical and radiologic disease in smokers with normal spirometry. JAMA Intern Med. 2015;175(9):1539-1549.

doi: https://doi.org/10.1001/jamainternmed.2015.2735

5. Schauer GL, Wheaton AG, Malarcher AM, Croft JB. Health-care provider screening and advice for smoking cessation among smokers with and without COPD: 2009-2010 National Adult Tobacco Survey. Chest. 2016;149(3):676-684.

doi: https://doi.org/10.1378/chest.14-2965

6. Wu P, Wilson K, Dimoulas P, Mills EJ. Effectiveness of smoking cessation therapies: a systematic review and meta-analysis. BMC Public Health. 2006;6:300.

doi: https://doi.org/10.1186/1471-2458-6-300

7. Quinn VP, Hollis JF, Smith KS, et al. Effectiveness of the 5-As tobacco cessation treatments in nine HMOs. JGen Intern Med. 2009;24(2):149154. doi: https://doi.org/10.1007/s11606-008-0865-9

8. National Center for Chronic Disease Prevention and Health Promotion (US) Office on Smoking and Health. Best Practices for Comprehensive Tobacco Control Programs. Centers for Disease Control and Prevention (CDC); 2014.

9. Park ER, Gareen IF, Japuntich S, et al. Primary care providerdelivered smoking cessation interventions and smoking cessation among participants in the National Lung Screening Trial. JAMA Intern Med. 2015;175(9):1509-1516.

doi: https://doi.org/10.1001/jamainternmed.2015.2391

10. Clark MA, Gorelick JJ, Sicks JD, et al. The relations between false positive and negative screens and smoking cessation and relapse in the National Lung Screening Trial: implications for public health. Nicotine Tob Res. 2016;18(1):17-24.

doi: https://doi.org/10.1093/ntr/ntv037

11. Friedman C, Brownson RC, Peterson DE, Wilkerson JC. Physician advice to reduce chronic disease risk factors. Am J Prev Med. 1994;10(6):367-371.

doi: https://doi.org/10.1016/S0749-3797(18)30567-1

12. Kim BS, Lim YH, Shin JH, et al. The impact of aversive advice during percutaneous coronary intervention on smoking cessation in patients with acute coronary syndrome. Glob Heart. 2019;14(3):253-257. doi: https://doi.org/10.1016/j.gheart.2019.04.001
13. Newhall K, Suckow B, Spangler E, et al. Impact and duration of brief surgeon-delivered smoking cessation advice on attitudes regarding nicotine dependence and tobacco harms for patients with peripheral arterial disease. Ann Vasc Surg. 2017;38:113-121.

doi: https://doi.org/10.1016/j.avsg.2016.06.005

14. Kerr S, Watson H, Tolson D, Lough M, Brown M. Smoking after the age of 65 years: a qualitative exploration of older current and former smokers'views on smoking, stopping smoking, and smoking cessation resources and services. Health Soc Care Community. 2006;14(6):572582. doi: https://doi.org/10.1111/j.1365-2524.2006.00659.x

15. Halpern MT, Warner KE. Differences in former smokers' beliefs and health status following smoking cessation. Am J Prev Med. 1994;10(1):31-37.

doi: https://doi.org/10.1016/S0749-3797(18)30644-5

16. Twardella D, Loew M, Rothenbacher D, Stegmaier C, Ziegler H, Brenner $\mathrm{H}$. The diagnosis of a smoking-related disease is a prominent trigger for smoking cessation in a retrospective cohort study. J Clin Epidemiol. 2006;59(1):82-89.

doi: https://doi.org/10.1016/j.jclinepi.2005.05.003

$\overline{\text { 17. Zeliadt SB, Heffner JL, Sayre G, et al. Attitudes and perceptions about }}$ smoking cessation in the context of lung cancer screening. JAMA Intern Med. 2015;175(9):1530-1537.

doi: https://doi.org/10.1001/jamainternmed.2015.3558

18. Regan EA, Hokanson JE, Murphy JR, et al. Genetic epidemiology of COPD (COPDGene) study design. COPD. 2010;7(1):32-43. doi: https://doi.org/10.3109/15412550903499522

19. Jones PW. St. George's respiratory questionnaire: MCID. COPD. 2005;2(1):75-79. doi: https://doi.org/10.1081/COPD-200050513

20. Ware JE, Jr, Sherbourne CD. The MOS 36-item short-form health survey (SF-36). I. Conceptual framework and item selection. Med Care. 1992;30(6):473-483.

doi: https://doi.org/10.1097/00005650-199206000-00002

21. Gilpin EA PJ, Goodman J, Burns D, Shopland D. Reasons smokers give for stopping smoking: do they relate to success in stopping? Tob Control. 1992;1:256-263.

doi: https://doi.org/10.1136/tc.1.4.256

22. Halpern MT, Warner KE. Motivations for smoking cessation: a comparison of successful quitters and failures. J Subst Abuse. 1993;5(3):247-256.

doi: https://doi.org/10.1016/0899-3289(93)90066-K

23. Pomerleau CS, Carton SM, Lutzke ML, Flessland KA, Pomerleau OF. Reliability of the Fagerstrom Tolerance Questionnaire and the Fagerstrom Testfor Nicotine Dependence. AddictBehav. 1994;19(1):3339. doi: https://doi.org/10.1016/0306-4603(94)90049-3

24. Wan ES, Hokanson JE, Murphy JR, et al. Clinical and radiographic predictors of GOLD-unclassified smokers in the COPDGene study. Am J Respir Crit Care Med. 2011;184(1):57-63. doi: https://doi.org/10.1164/rccm.201101-00210C 
25. Wan ES, Castaldi PJ, Cho MH, et al. Epidemiology, genetics, and subtyping of preserved ratio impaired spirometry (PRISm) in COPDGene. Respir Res. 2014;15(1):89.

doi: https://doi.org/10.1186/s12931-014-0089-y

26. McCaul KD, Hockemeyer JR, Johnson RJ, Zetocha K, Quinlan K, Glasgow RE. Motivation to quit using cigarettes: a review. Addict Behav. 2006;31(1):42-56.

doi: https://doi.org/10.1016/j.addbeh.2005.04.004

27. Anthonisen NR, Connett JE, Kiley JP, et al. Effects of smoking intervention and the use of an inhaled anticholinergic bronchodilator on the rate of decline of $\mathrm{FEV}_{1}$. The lung health study. JAMA. 1994;272(19):1497-1505.

doi: https://doi.org/10.1001/jama.1994.03520190043033

28. Centers for Disease Control and Prevention (CDC). The Surgeon General's 1990 report on the health benefits of smoking cessation. Executive summary. MMWR Recomm Rep. 1990;39(RR-12):i-xv, $1-12$.

29. Sullivan PF, Kendler KS. The genetic epidemiology of smoking. Nicotine Tob Res. 1999;1(Suppl 2):S51-57.

doi: https://doi.org/10.1080/14622299050011811

30. Hancock DB, Reginsson GW, Gaddis NC, et al. Genome-wide metaanalysis reveals common splice site acceptor variant in CHRNA4 associated with nicotine dependence. Transl Psychiatry. 2015;5:e651. doi: https://doi.org/10.1038/tp.2015.149 